\title{
The influence of accountability for the crisis and type of crisis communication on people's behavior, feelings and relationship with the government
}

\author{
Marije H. Bakker ${ }^{\mathrm{a}, *}$, Marco van Bommel ${ }^{\mathrm{a}}$, José H. Kerstholt ${ }^{\mathrm{a}, \mathrm{b}}$, Ellen Giebels ${ }^{\mathrm{a}}$ \\ a University of Twente, Department of Psychology of Conflict, Risk and Safety, PO BOX 217, 7500 AE Enschede, The Netherlands \\ b TNO, PO BOX 23, 3769 ZG Soesterberg, The Netherlands
}

\section{A R T I C L E I N F O}

\section{Keywords:}

Crisis communication

Empathic information

Accountability

Collective efficacy

Self-reliant behavior

\begin{abstract}
A B S T R A C T
In this paper we investigated to what extent the willingness of people to take advice from the local government, people's feelings of collective efficacy and empowerment, and their relationship with the local government, is dependent on whether the local government was accountable for the crisis or not. In addition, we were interested in the influence of empathic versus neutral crisis information on people's behavior, feelings and their relationship with the local government. The results indicate that people's intention to follow the advice of the local government is generally high, even when the local government is held accountable for the crisis. However, accountability negatively influenced people's relationship with the local government, as well as collective efficacy. Our research shows that this negative outcome for people's relationship with the local government cannot be countered by empathic crisis information. However, conveying empathic concern in the crisis information did enhance level of collective efficacy.
\end{abstract}

\section{Introduction}

People live in a society that is affected by a broad range of crisis situations, such as floods, industrial fires and terrorist attacks. Regardless of where one lives, many different types of crisis have the potential to disrupt people's daily life (Ulmer, Sellnow, \& Seeger, 2013). There are two prominent factors that influence people's reactions during a crisis, namely who or what is held accountable for the crisis, and the type of information people receive about the crisis (e.g., Coombs, 2004; Steelman, McCaffrey, Velez, \& Briefel, 2015).

Accountability can broadly be attributed to internal or external factors. When the cause of the crisis is attributed to internal factors, a person or organization is held accountable for the cause of the crisis. Attributions to external factors include situations with a low accountability attribution to a person or organization, such as a crisis caused by technical errors (e.g., Coombs, 2007). These categories are important as research shows that attributions about who or what is accountable for a crisis shape feelings and behaviors (Coombs, 2004; Jin, Liu, \& Austin, 2014; Lee, 2004). Moreover, it may change the relationship between people and the organization that is held accountable for the crisis. The organization, for instance, may seem as less trustworthy or less competent (e.g., Becker, Paton, \& Johnston, 2015; Cuddy, Glick, \& Beninger, 2011). There is a leading theory that investigates relational maintenance strategies (e.g., Broom, Casey, \& Ritchey, 1997; Broom, Casey, \& Ritchey, 2000; Ledingham \& Bruning, 1998), but the key driving theory in this study is the attribution theory, because attributions underlie how a relationship is perceived.

\footnotetext{
* Corresponding author.

E-mail addresses: m.h.bakker@utwente.nl (M.H. Bakker), m.vanbommel@utwente.nl (M. van Bommel), jose.kerstholt@tno.nl (J.H. Kerstholt), e.giebels@utwente.nl (E. Giebels).
} 
How people respond to a crisis, however, depends not only on who is held accountable for the crisis, but it is also influenced by the information people receive. Typically, crisis information contains facts about the situation and advises on how to deal it (Reynolds \& Seeger, 2005; Steelman \& McCaffrey, 2013). However, Sutton, Palen, and Shklovski (2008) reasoned that crises also create a need for empathy. Expressing empathy during crisis is important as it demonstrates recognition of and concern for the people that are suffering (Fehr \& Gelfand, 2010), which may lead to a better relationship between people, and the organization and a stronger influence of crisis information on people's behavior (Seeger, 2006).

The current research aims to investigate to what extent people's behavior, feelings of collective efficacy and empowerment, and their relationship with the organization is influenced by accountability for the crisis and the type of crisis communication. We focus on the local government as organization, as the local government usually sends crisis information, and they are primary accountable for public security in the Netherlands. Up to now, research mostly investigated the effect of accountability for a crisis when the organization was a commercial company (the private sector) (Coombs, 2004, 2007). However, it is worthwhile to also examine what the effect of accountability for a crisis is when the organization is the local government (the public sector), because in times of crisis the (local) government is usually accountable for communicating proper and trustworthy crisis communication. Once trust is lowered due to accountability, it is possible that people will also have less trust in this information. Empathic crisis communication may restore the relationship between people and the local government. In an experimental study involving a fictitious large-scale fire with hazardous substances, we manipulated whether the local government was accountable for the crisis or not and whether the crisis communication was framed as neutral or empathic.

\subsection{Crisis accountability}

Who or what is held accountable for a crisis may influence how people respond to the crisis and how they view the actors involved in the situation. The rationale for this notion lies in attribution theory, which holds that people make judgments about the causes of a situation, especially when the situation is unexpected and has negative outcomes, such as crisis situations. People will attribute the cause of an event either to an individual or organization involved in the event or to external circumstances. Attributions indicate whether someone believes that the cause of the crisis is within the control of people or an organization involved (Coombs, 2004, 2007). If people believe, for instance, that an organization could control a crisis, they will also hold the organization responsible for the crisis (Lee, 2004).

Causal attributions are important because they affect emotions generated by the event and future interactions with the person or organization involved (Coombs, 2004, 2007). Lee (2004), for example, found that when an organization is responsible for a crisis, people are more likely to form negative impressions of the organization, tend to be less sympathetic toward the organization and have less trust in the organization. In addition, McDonald, Sparks, and Glendon (2010) describe an association between crisis responsibility and negative feelings, and behavioral intentions.

\subsection{Framing crisis communication}

People's behavior and attitude in response to a crisis is not only influenced by crisis accountability, but also by the information they receive during a crisis. During a crisis, the local government provides crisis information to enable people to adequately deal with the crisis (e.g., Lindell \& Perry, 2012; Stubbé, Emmerik, \& Kerstholt, 2017). Telling people about the crisis situation and what they can do to reduce their harm can help restore some sense of control over an uncertain and threatening situation (Seeger, 2006). More recently, however, researchers suggested that crises not only create a need for information, but also for human conversation (Sutton et al., 2008).

A way to introduce "a human voice" in crisis communication is by expressing empathy. Although the definition of empathy has been much discussed, most researchers view empathy as having both cognitive and affective elements (e.g., Davis et al., 2004; Eisenberg \& Miller, 1987). Cognitive empathy refers to perspective taking, the cognitive capacity to consider the world from another individual's viewpoint. Affective empathy refers to empathic concern, the ability to understand and share emotions with someone else. It is also often labeled as expressing sympathy or compassion (Shen, 2010).

There has been sporadic evidence for the persuasive impact of empathy-based information. Most studies on this topic are focused on messages that advocate pro-social behaviors that concern others' well-being, as reflected in the topics they considered (e.g., organ donation, Bae (2008)). Less is known about the persuasive effect of empathy when the message is relevant to one's own well-being (Shen, 2010). There is, however, some evidence that indicates that including empathy in a message has several positive consequences. Firstly, Shen (2010) suggested that when information induces empathy, this leads to more similarity and a better relationship between the sender and receiver of the information. Additionally, a good relationship increases the persuasiveness of the information for behavior (Faraji-Rad, Samuelsen, \& Warlop, 2015; Silvia, 2005; Steelman et al., 2015). Secondly, when a person receives empathy expressing information this may reduce negative affective responses, such as anger (Decety \& Jackson, 2004; Shen, 2010). Thirdly, expressing empathy may also lead to higher levels of trust in the sender and people may respond more positively (i.e., people have more faith that the recommended actions are appropriate and legitimate) to spokespersons who acknowledge their concerns and show compassion for any harm that may have occurred (De Waal, 2008; Seeger, 2006; Sweetser \& Metzgar, 2007).

\subsection{Stimulating resilient communities}

The relationship between citizens and professionals in crisis management is becoming more and more important, as a result of 
societal changes like citizen empowerment and attention for strengthening community resilience (Duijnhoven, Neef, Davis, Dinesen, \& Kerstholt, 2016). Responsibility for the safety of people is not a matter exclusively for the local government anymore and local governments expect that people themselves contribute to their own safety during and after a crisis. The benefits of empowering citizens and strengthening community resilience are, for example, more self-reliant behavior during and after a crisis, decreased recovery time, better community responses to warnings, less victims and less damages (Becker et al., 2011, 2015).

One of the most important factors identified as stimulating resilient communities is collective efficacy. Collective efficacy is the belief that collectively a community can effectively deal with a crisis (Norris, Stevens, Pfefferbaum, Wyche, \& Pfefferbaum, 2008; Paton, 2013). During a crisis, communities with high levels of collective efficacy are able to coordinate efforts toward recovery, can effectively manage resources, are able to generate strategic plans and are more resilient during crisis (Benight, 2004).

Collective efficacy is highly related to empowerment (Perkins, Hughey, \& Speer, 2002). Empowerment describes people's feelings of personal competence and confidence to deal with issues that arise (Norris et al., 2008). The local government can empower people by providing information about how to deal with a crisis. People who feel more empowered by the local government feel themselves more capable to prepare for and to respond to a crisis, which makes them more likely to follow the local government's advice (Becker et al., 2015).

\subsection{Relationship between people and the local government}

Research shows that besides crisis information, the quality of the relationship between people and the local government also influences decisions to act (Coombs, 2004; Lindell \& Whitney, 2000; Paton, Smith, Daly, \& Johnston, 2008; Reynolds \& Seeger, 2005; Seeger, 2006). Research in other governmental contexts also showed the importance of a good relationship between people and the government for decision-making. Lee Jenni, Peterson, Katz Jameson, and Cubbage (2015), for instance, showed that a good military-public relation leads to more trust, positive sentiments, and more sustainable decisions with regard to environmental issues in military contexts. Ledingham (2001) studied government-community relationships and found that effective public relations can contribute to community building, when points of common interest between the government and the public are identified.

In the following section we will reason that trust and closeness are important influences on the relationship between people and the local government.

Trust has been conceptualized in many ways, but in line with a number of authors (Frewer, Howard, Hedderley, \& Shepherd, 1996; Peters, Covello, \& McCallum, 1997; Renn \& Levine, 1991), we conceptualize trust as a multidimensional construct that consists of 'competence', 'openness, honesty and expertise', and 'concern and care'. When the local government is not trusted, the value of the information will strongly reduce (Pieniak, Verbeke, Scholderer, Brunsø, \& Olsen, 2007; Seeger, 2006; Steelman \& McCaffrey, 2013). Consequently, having trust in the local government is important for motivating people to act upon a crisis (Becker et al., 2015; Cuddy, Fiske, \& Glick, 2008; Fiske, Cuddy, \& Glick, 2007; Siegrist, 2000).

Closeness is another factor that determines whether people are willing to follow the advice of the government. Closeness describes the interdependence between two people in terms of support, shared interests, and self-disclosure (Parks \& Floyd, 1996). Close relationships are important for human experience and behavior as it, for example, provides safety and emotional support (Aron, Aron, \& Smollan, 1992; Baumeister \& Leary, 1995). Typically closeness measures have been used to assess closeness in romantic relationships (Aron et al., 1992), but more recent work also used the scale to determine the level of closeness across various interpersonal relationships which are not romantic in nature (Li, Zhang, Bhatt, \& Yum, 2006; Woosnam, 2010).

\subsection{Present study}

Crisis situations differ in several ways, but an important factor is who or what is held accountable for the crisis. Who or what is held accountable may influence how people respond to the crisis. However, the reaction of people is not only dependent on this issue about accountability, as previously mentioned, it also depends on the way the crisis communication is conveyed. Therefore, in this study we examined the influence of accountability for a crisis (government accountable versus government not accountable) and type of crisis communication (neutral versus empathic) on people's willingness to take advice from the local government, people's feelings of collective efficacy and empowerment, and the relationship between people and the local government.

In line with research of Coombs (2004) and Jin et al. (2014), it was predicted that:

When the local government is held accountable for the crisis, people have a stronger negative affect (H1a), experience lower levels of collective efficacy (H1b) and empowerment (H1c), and the relationship with the local government is more negatively affected (in terms trust (H1d) and closeness (H1e)), compared to a local government that is not held accountable for the crisis

Based on research of Coombs (2004, 2007), Lee (2004), and McDonald et al. (2010) we hypothesized that:

When the local government is held accountable for the crisis, people have less trust in the message of the local government, and consequently this lead to less willingness to follow the advice of the local government, compared with a crisis for which the local government is not held accountable (H2) 
Based on previous research (e.g., Faraji-Rad et al., 2015; Seeger, 2006; Shen, 2010), we expect the following regarding type of crisis communication:

$\mathrm{H} 3$

Empathically framed crisis information will result in higher willingness to follow the advice of the local government (H3a), less negative affect (H3b), higher scores on collective efficacy (H3c) and empowerment (H3d), and a better relationship between people and the local government (i.e., higher scores on trust (H3e) and closeness (H3f)), compared with the neutrally framed crisis communication.

Finally, we were interested in the interaction between who is held accountable for the crisis and type of crisis communication. In times of crisis, the local government is responsible for communicating clear and trustworthy crisis information. How people respond to this crisis information may be influenced when the local government is held accountable for the crisis and may be influenced by the type of crisis communication. Therefore, we predict that:

$\mathrm{H} 4$

The effect of the type of crisis communication (neutral or empathic) is dependent upon whether the local government is held accountable for the crisis for willingness to follow the advice of the local government, negative affect, collective efficacy, empowerment, trust and closeness (H4).

\section{Method}

\subsection{Design and participants}

An online experiment was run to investigate to what extent accountability for the crisis and the type of crisis communication influences people's reaction to the crisis. The study was a 2 (accountability: government accountable or government not accountable) x 2 (crisis communication: empathic or neutral) between subjects design. Data were collected from 164 participants using a convenience sample from Dutch-speaking men and women who lived in the Netherlands. We excluded 11 participants who did not complete the whole questionnaire, leaving 153 participants for statistical analyses $\left(M_{\mathrm{age}}=41.75, S D_{\text {age }}=14.14 ; 95\right.$ females, 58 males). No differences were found between the four conditions for gender, $\chi^{2}(3)=2.29$, ns., age, $F(3149)=0.69$, ns., education $\chi^{2}(18)=21.16$, ns., or prior experience with a fire involving hazardous substances, $F(3149)=0.84$, ns. Participants indicated via self-report (seven-point Likert scale, 1 (not at all) - 7 (very much)) that they were in general able to imagine the crisis situation, $M=5.50, S D=0.87$ and they rated the crisis as realistic, $M=5.72, S D=0.97$.

\subsection{Procedure}

Participants were randomly divided across the four experimental conditions. First, participants had to read a short vignette about a fire at a company that worked with hazardous substances. They read that the fire raged in an industrial area close to their homes (see Appendix A). Subsequently, to increase immersion and vividness of the vignette, participants watched a short video clip of the fire.

After the scenario, participants received information about who or what was held accountable for the crisis. Half of the participants received information that the local government was negligent regarding the storage of large amounts of chemicals in the building. The local government illegitimately provided the company permit and the cause of the fire was due to the local government's negligence to perform proper safety checks. The other half received information that the local government regularly checked the storage of large amounts of chemicals in the building. The local government provided the company legitimately a permit and performed proper safety checks, however the cause of the fire was due to a technical error in a machine, which could not possibly have been foreseen.

After reading information about who was held accountable for the fire, participants received crisis information from the local government about the actual situation and advices were given about self-protective actions. Half of the participants received neutral crisis communication, whereas the other half received empathic crisis communication (see Appendix A). The neutral crisis information was based on the crisis communication that was released during a large-scale fire at Chemie-pack in Moerdijk (Joustra, Brouwer-Korf, Mertens, Muller, \& Visser, 2012). The empathic crisis information was based on the best crisis communication practices of Seeger (2006). Three sentences to induce empathy were used, e.g., 'Our thoughts are with everyone affected by this fire'. Finally, participants had to fill out a questionnaire.

\subsection{Measures}

All questions in the questionnaire were measured on seven-point Likert type scales, with the exception of the measurement of closeness, which was a multiple-choice question.

\subsubsection{Manipulation checks}

2.3.1.1. Accountability.. The accountability scale was based on a previous study conducted by Griffin, Babin, and Darden (1992). Participants reported to what extent the local government was held accountable for the crisis. Questions were asked like: 'The local government is accountable for the fire' and 'The local government is to blame for the cause of the fire' (scale: $1=$ totally disagree $7=$ totally agree; $\alpha=0.95$ ). 
2.3.1.2. Empathy.. The empathy scale was newly developed. Participants were asked to what extent they agreed that the local government expressed sympathy, empathy and showed compassion in their crisis information (scale: $1=$ totally disagree $7=$ totally agree; $\alpha=0.91$ ).

\subsubsection{Dependent variables}

2.3.2.1. Follow the advice. Three items measured willingness to follow the advice of the local government. The items were based on a study of Gutteling and De Vries (2016). An example item is 'How likely is it that you follow the advice of the local government' (scale: $1=$ not at all $-7=$ very; $\alpha=0.79$ ).

2.3.2.2. Negative affect. Participants reported their negative affect with respect to the fire in terms of feeling tense, anxious, nervous, concerned, angry and sad (scale: $1=$ not at all $-7=$ very much; $\alpha=0.85$ ). Participants who scored high on negative affect were more worried about the crisis situation. Negative affect measures were adapted from Wiegman and Gutteling (1995).

2.3.2.3. Collective efficacy.. Collective efficacy was based on a study of Paton (2013). Participants were asked to what extent they had the feeling that they collectively were able to do something to control the outcome of a crisis. A three-item scale was used, e.g., 'I have the feeling that we collectively can deal effectively with this crisis' (scale: $1=$ totally disagree $-7=$ totally agree; $\alpha=0.89$ ).

2.3.2.4. Empowerment. Three items measured empowerment (Paton, 2013). Based on the information during the fire, participants were asked to what extent they felt they were able to influence what was happening. One item showed low inter-item correlations with the other measures in the scale and was consequently deleted (scale: $1=$ not at all $-7=$ very much; $r=0.52$, $\mathrm{p}<.001$ ).

2.3.2.5. Trust in local government. Based on studies of Rosenberg, Nelson, and Vivekananthan (1968) and Regan et al. (2014) trust was measured using three dimensions of trust: 'competence', 'openness, honesty and expertise', and 'concern and care'. Participants were asked to what extent they characterize the local government as, for example, helpful, sincere, intelligent, skillful, accurate and credible. Pairwise correlations among these dimensions were high (Range $r(153)=0.82-.85, p<.001$ ), and a Principle Components factor analysis on the three dimensions revealing one underlying factor (based on Eigenvalues greater than 1) that explained $65.37 \%$ of the variance. Consequently, we decided to create a trust scale by averaging the scores on these three dimensions, which showed high internal consistency (scale: $1=$ not at all $-7=$ very much, Cronbach's $\alpha=0.96$ ). A higher score on this scale means that the participant had more trust in the local government.

2.3.2.6. Closeness to the local government. Based on the Inclusion of Others in Self scale (Aron et al., 1992), participants were asked to choose the pair of circles that best portrays their relationship with the local government. This measurement consisted of seven pairs of circles whereby each pair overlapped each other slightly more than the preceding pair (scale: $1=$ far apart $-7=$ highly overlapping).

Finally, questions were asked about the ability to imagine the situation and prior experiences with a fire involving hazardous substances. Demographics were collected about their age (in years), gender (male $=0$, female $=1$ ), and education level.

\section{Results}

\subsection{Manipulation checks}

A pre-test with university students and personnel was conducted to check the manipulation of the accountability frame and type of crisis communication $(N=20)$. The results of an independent-samples $t$-test show that when the local government was held accountable for the crisis, participants considered the local government as more accountable $(M=4.60, S D=0.70)$, than when the local government was not held accountable for the crisis $(M=1.90, S D=1.32), t(18)=-5.70, p<.001$. In addition, consistent with the manipulation of type of crisis communication, when the information was framed in an empathic manner, participants considered the communication to be significantly more empathic $(M=4.37, S D=1.38)$, than when the message was framed as neutral $(M=2.50, S D=1.33), t(18)=-3.08, p=.006$.

For the experiment, a manipulation check of the accountability frame and type of crisis communication was also conducted and yielded similar results. The findings indicate a significant main effect of accountable frame on accountability, $F(3149)=698.51$, $p<.001$. Accountability was perceived as considerably higher in the accountable condition $(M=5.44, S D=0.09)$, compared to the no-accountable condition $(M=2.02, S D=0.09)$. In addition, a main affect was found for type of crisis communication on empathy, $F(3149)=698.51, p<.001$. Participants perceived the empathic-framed crisis communication as more empathic $(M=4.62$, $S D=0.17)$, than when the message was framed as neutral $(M=3.14, S D=0.17)$. There were no interaction effects.

\subsection{Means and correlations}

Participants scored quite high on willingness to follow the advice of the local government $(M=5.80)$. Willingness to follow the advice correlates positively with collective efficacy $(r=0.35)$, trust $(r=0.32)$, and closeness $(r=0.35)$. See Table 1 for the means, standard deviations, and the correlations among all dependent variables. 
Table 1

Means and Pearson correlations.

\begin{tabular}{|c|c|c|c|c|c|c|c|c|}
\hline & & M & SD & 1. & 2. & 3. & 4. & 5. \\
\hline 1. & Willingness to follow advice & 5.80 & 1.19 & & & & & \\
\hline 2. & Negative affect & 3.95 & 1.23 & .03 & & & & \\
\hline 3. & Collective efficacy & 4.79 & 1.37 & $.35^{* *}$ & -.10 & & & \\
\hline 4. & Empowerment & 2.52 & 1.44 & .08 & -.01 & $.28^{* *}$ & & \\
\hline 5. & Trust & 4.00 & 1.27 & $.32^{* *}$ & $-.22^{* *}$ & $.47 * *$ & $.28 * *$ & \\
\hline 6. & Closeness & 3.98 & 1.16 & $.35^{* *}$ & $-.17^{*}$ & $.47^{* *}$ & $.27^{* *}$ & $.46^{* *}$ \\
\hline
\end{tabular}

Significance levels: ${ }^{*} p<.05, * * p<.001, N=153$.

\subsection{Hypothesis testing}

To learn more about the influence of accountability frame and type of crisis communication on the dependent variables; willingness to follow the advice of the local government, negative affect, collective efficacy, empowerment, trust, and closeness, analysis of variance was applied. See Table 2 for the means and standard deviations across the conditions.

\subsubsection{Effects of crisis accountability}

There was no significant main effect for the accountability frame on negative affect, $p=0.238$, implying that negative affect was not influenced by whether the government was held accountable for the crisis. This means that H1a, stating that when the government is held accountable for the crisis, people have a stronger negative affect, was not supported.

There was a marginal main effect for the accountability frame on collective efficacy, $F(3,149)=3.09, p=.081$, partial $\eta^{2}=0.02$. Participants in the accountable condition had less the feeling that they collectively were able to do something to control the outcome of the crisis $(M=4.60)$, than those in the no-accountable condition $(M=4.98)$. H1b was thus confirmed.

There was no main effect for the accountability frame on empowerment, $p=.187$. Hypothesis H1c was therefore not supported.

A significant main effect was found for the accountability frame on trust, $F(3,149)=18.14, p<.001$, partial $\eta^{2}=0.11$. Participants in the accountable condition scored lower on trust in the local government $(M=3.62)$, compared with participants in the no-accountable condition $(M=4.37)$. H1d was thus confirmed.

A marginal main effect was found of the accountability frame on closeness to the local government, $F(3,149)=3.78, p=.054$, partial $\eta^{2}=0.03$. Participants in the no-accountable condition felt more closeness to the local government $(M=3.17)$, than participants in the accountable condition $(M=2.78)$. This result confirms H1e.

To investigate whether trust mediates the relationship between accountability frame and willingness to follow the advice of the local government, we performed a mediation analysis. The first regression analysis with willingness to follow the advice of the local government as dependent variable and accountability frame as the predictor yielded an insignificant relation $(b=0.37, S E=0.19$, $p>.05,95 \%$ CI $[-0.01 ; 0.75]$. Therefore, H2 was not supported.

\subsubsection{Effects of type of crisis communication}

There were no significant main effects of type of crisis communication on willingness to follow the advice of the local government, $p=.348$, and negative affect, $p=.399$. Therefore, H3a and H3b were rejected.

A significant main effect was found of type of crisis communication on collective efficacy, $F(3,149)=4.19, p=.042$, partial $\eta^{2}=0.03$. Participants who received the empathic crisis information scored higher on collective efficacy $(M=5.01)$, compared with participants who received neutral crisis information $(M=4.56)$. There results confirmed H3c.

There were no significant main effects of type of crisis communication on empowerment, $p=.620$, trust, $p=.365$, and closeness, $p=.158$. Therefore, H3d, H3e and H3f were rejected.

Table 2

Means and standard deviations per accountability frame and type of crisis communication frame.

\begin{tabular}{|c|c|c|c|c|c|c|c|c|}
\hline & \multicolumn{4}{|c|}{ Accountability } & \multicolumn{4}{|c|}{ Type of crisis communication } \\
\hline & \multicolumn{2}{|c|}{ Government accountable } & \multicolumn{2}{|c|}{ Government not accountable } & \multicolumn{2}{|c|}{ Neutral } & \multicolumn{2}{|c|}{ Empathic } \\
\hline & $M$ & $S D$ & $M$ & $S D$ & $M$ & $S D$ & $M$ & $S D$ \\
\hline Willingness to follow advice & 5.84 & 1.15 & 5.76 & 1.23 & 5.71 & 1.30 & 5.89 & 1.06 \\
\hline Negative affect & 4.07 & 1.24 & 3.84 & 1.21 & 4.04 & 1.22 & 3.87 & 1.25 \\
\hline Collective efficacy & 4.59 & 1.39 & 4.98 & 1.33 & 4.57 & 1.33 & 5.01 & 1.38 \\
\hline Empowerment & 2.36 & 1.27 & 2.67 & 1.59 & 2.45 & 1.27 & 2.58 & 1.61 \\
\hline Trust & 3.62 & 1.16 & 4.37 & 0.98 & 3.92 & 1.18 & 4.08 & 1.08 \\
\hline Closeness & 2.77 & 1.23 & 3.17 & 1.26 & 2.83 & 1.28 & 3.12 & 1.22 \\
\hline
\end{tabular}

$N=153$. 


\subsubsection{Interaction effects}

The interaction between crisis accountability and type of crisis communication was found to be insignificant for all dependent variables, all $p$ 's $>.139$. Hypothesis 4 was therefore rejected.

\section{Discussion}

In this study we examined the influence of accountability for the crisis and type of crisis communication on people's willingness to follow the advice of the local government, feelings of collective efficacy and empowerment, and people's relationship with the local government (i.e., trust and closeness to the local government). Overall, we found effects of both accountability for the crisis and type of crisis communication. When the local government is held accountable for the crisis, then the relationship between people and the local government is undermined in terms of trust and closeness, and it leads to reduced feelings of collective efficacy. Furthermore, the type of crisis communication has less influence on people's behavior, feelings and their relationship with the local government; empathic crisis information only leads to stronger feelings of collective efficacy.

\subsection{Effects of accountability}

More specifically, we did not find a difference on willingness to follow the advice of the local government, between a crisis where the local government was held accountable for the crisis, and a crisis where the government was not held accountable for the crisis. This finding is in contrast with research of McDonald et al. (2010), who argued that crisis accountability and behavioral intentions are associated with each other. A possible explanation for this difference in result is the difference in crisis scenarios. We used a scenario where people themselves were involved in the crisis: people were asked to imagine that a large-scale fire with hazardous substances rages close to their homes. McDonald et al. (2010) used a scenario where people not directly were involved in the crisis: people were asked to imagine that an airplane had crashed which they or their loved ones recently used. We expect that the need to do something against the crisis was much larger in our scenario (due to the direct involvement), than in the scenario of McDonald et al. (2010). Therefore, who or what is accountable for the crisis did not make any difference on willingness to follow the advice of the local government.

Accountability frame did have an influence on collective efficacy. Participants scored lower on collective efficacy when the local government was accountable for the crisis. A consequence of lower levels of collective efficacy is that people have less trust that they collectively can do something to control the outcome of a crisis (Benight, 2004; Norris et al., 2008).

With respect to the relationship variables, our results showed effects of accountability frame on trust, and closeness to the local government. When the local government was held accountable for the crisis, participants scored lower on trust in the local government, and they felt less close to the local government, compared with the scenario where the local government was not held accountable for the crisis. This was in line with our expectations. The more people attribute a negative event to the organization involved, the more negative they are towards that organization (e.g., Coombs, 2014). In addition, trust and closeness to the local government correlated positively with the willingness to follow the advice of the local government. The correlation between trust and willingness to follow the advice of the local government is consistent with the literature (e.g., Becker et al., 2015; Pieniak et al., 2007; Seeger, 2006). Having trust in the local government is important for motivating people to act upon a crisis (Becker et al., 2015; Siegrist, 2000). Finally, the correlation between closeness and willingness to follow the advice of the local government is in line with research of Baumeister and Leary (1995), who described that close relationships are important for behavior, as it provides safety and emotional support.

\subsection{Effects of crisis communication}

Regarding the crisis communication frame, it was expected that participants were more willing to follow the advice of the local government when they received empathic crisis information, than participants who received neutral crisis information (e.g., Seeger, 2006; Shen, 2010). This is not in line with our results, as we found no effect of the crisis communication frame on willingness to follow the advice of the local government. We suggest that in 'the heat of the moment' people only need information that helps them to deal adequately with the crisis. Expressing empathy in crisis information does not provide that first need. Therefore, we suggest that expressing empathy is more important in the aftermath of a crisis, as it is a way to apologize for any harm that may have occurred (Claeys, Cauberghe, \& Leysen, 2013). This implies that it is the content of the information that determines whether people decide to act upon a crisis, and not the way the crisis information is framed.

However, crisis communication frame did have an influence on collective efficacy. Our results showed that the participants who received empathic crisis information felt more able to deal collectively with the crisis, compared with participants who only received neutral crisis information. Probably, empathic information leads to a better understanding between people and the local government, which also influence people's belief that a community together can do something to mitigate the effects of a crisis (Norris et al., 2008; Shen, 2010; Silvia, 2005). This is an important result as collective efficacy is identified as one of the most important factors in stimulating resilient communication (Becker et al., 2015; Benight, 2004).

No effects were found for the crisis communication frame on the relationship variables. Expressing empathy in crisis information did not lead to more trust in the local government, and more closeness to the local government. This contrasts with findings of Shen (2010), who found that when information express empathy a better relationship with the sender of the information is obtained. We suggest that it takes more effort to influence levels of trust and closeness; just one message is not enough. 


\subsection{Limitations and future research}

While this study uncovered novel insights into the influence of accountability for a crisis and type of crisis communication, we wish to acknowledge some limitations of this experimental study. First of all, this study used a convenience sample of the general population that could limit the scope of our findings. However, we considered it important not to do a study with the often-used student sample as students differ from the general population: students have a weaker self-definition, and consequently they have weaker attitudes that are more easily influenced and less predictive of behavior than those of the general population (Petty \& Cacioppo, 1996). Another limitation concerning the generalizability of our results is that we used one specific crisis situation, a fire with hazardous substances. In real life, most crisis situations are far more complex, with a broad range of response options, more confusion about what exactly is going on and people interacting with each other. Although participants experienced the fire as realistic, it is not the same as experiencing an actual crisis situation. Another limitation of our results concerns the measurement of willingness to follow the advice of the local government, as we asked for behavioral intentions. Research often indicates that behavioral tendencies do not always correlate strongly with actual behavior (Baumeister, Vohs, \& Funder, 2007; Warshaw \& Davis, 1985). However, other work specifically in the safety domain, for instance Paton et al. (2010) demonstrated that intention actually is a good predictor for behavior. As the literature does not provide an unequivocal answer, follow-up research is needed to reveal whether the effects as found in the present study also hold for a study where actual behavior is measured. To measure actual behavior, a field experiment can be conducted or virtual reality can be used in which a crisis situation is simulated.

Finally, researchers could see the rejection of several hypotheses in this study as a limitation. Some of the results were in contrast with what we expected based on previous studies, for instance, in our study the willingness to follow the government's advice was not dependent on whether or not the government was accountable for the crisis. Indeed, one must interpret such nonsignificant findings with care as they could have several implications. One implication of these contrasting null results could be that the number of participants in our experiment was too small, resulting in low power. However, with on average forty participants per condition, the current study had ample power to detect even medium effects sizes (see for instance VanVoorhis and Morgan (2007)). Another implication of these contrasting null results lies in the methodology; moderators such as another research population and differences in research methods between studies (e.g., vignettes versus field experiment, long manipulation texts versus short manipulation texts) could all lead to different outcomes. Recently, studies with statistically significant results were more likely to be published than those studies supporting the null hypothesis (Fanelli, 2010). Publishing non-significant results are important when it makes a significant contribution to the literature, and when the study is methodologically well designed. Knowledge of non-significant results can then, just like knowledge of significant results, be used as a starting point for new research.

\section{Conclusion}

Taken together, our findings indicate that in general people's intention to follow the advice of the local government is high, even when the local government is held accountable for the crisis. However, accountability negatively influenced people's relationship with the local government and lowered people's collective efficacy, i.e., their believe that they collectively can do something to mitigate the consequences of the crisis. Our research shows that this negative outcome for people's relationship with the local government cannot be countered by empathic crisis information. However, conveying empathic concern in the crisis information enhances levels of collective efficacy in general.

\section{Appendix A. Manipulations}

\section{Scenario}

Imagine that you are at home and black clouds of smoke are moving for a while over your home and you wonder what is going on. On a news app on your phone you read that a large-scale fire is raging at a company close to your home. The company was set on fire after an explosion, and in the meanwhile the fire has been spread to two adjacent warehouses. The strong wind causes high flames. You hear explosions, possibly caused by chemicals that are stored in the warehouse. The fire brigade fights the fire, but it isn't under control yet. Due to the strong wind enormous clouds of smoke are moving over the region. At this moment it isn't clear what the consequences are of the fire and the smoke.

\section{Manipulation accountability}

Local government accountable

The fire started in a warehouse that worked with chemicals and is located in an industrial area near a densely populated area. The local government was careless in the control of the storage of large amounts of chemicals in the warehouse. The company did not fulfill all safety requirements and the obtained license from the local government was unjustified. The cause of the fire was due to failing safety checks.

Local government not accountable

The fire started in a warehouse that worked with chemicals and is located in an industrial area near a densely populated area. The local government has checked regularly the storage of large amounts of chemicals in the warehouse. The company fulfilled all safety requirements and the obtained license from the local government was justified. The cause of the fire was due to a technical problem in one of the machines. 


\section{Manipulation type of crisis communication}

Neutral

Today, our region is startled by the large-scale fire with toxic chemicals, such as ammonia and methanol. Enormous clouds of smoke are moving over our region. To ensure the safety of all residents, we will inform you at an early stage about the situation. At this moment we don't know whether the smoke contains hazardous substances, but nevertheless we recommend the following: 1) don't go outside to watch the fire, 2) go inside and close windows, doors and ventilation shafts, 3) switch off the mechanical ventilation, 4) stay inside a room that can be sealed off, preferably in the middle of the house. The present state of affairs concerning the fire is that the fire brigade fights the fire, but it isn't under control yet. Air samples are taken to collect information concerning the presence and the risk of hazardous materials. Stay informed about the latest developments; follow the news or visit www.crisis.nl.

Empathic

Today, our region is startled by the large-scale fire with toxic chemicals, such as ammonia and methanol. Enormous clouds of smoke are moving over our region. We understand that you, as a resident, are concerned about the situation and the possible consequences of this fire. To ensure the safety of all residents, we will inform you at an early stage about the situation. At this moment we don't know whether the smoke contains hazardous substances, but nevertheless we recommend the following: 1) don't go outside to watch the fire, 2) go inside and close windows, doors and ventilation shafts, 3) switch off the mechanical ventilation, 4) stay inside a room that can be sealed off, preferably in the middle of the house. We understand that these measures may cause inconvenience. The present state of affairs concerning the fire is that the fire brigade fights the fire, but it isn't under control yet. Air samples are taken to collect information concerning the presence and the risk of hazardous materials. Stay informed about the latest developments; follow the news or visit www.crisis.nl. Our thoughts are with everyone affected by this fire.

\section{References}

Aron, A., Aron, E. N., \& Smollan, D. (1992). Inclusion of Other in the Self Scale and the structure of interpersonal closeness. Journal of Personality and Social Psychology, 63(4), 596-612. http://dx.doi.org/10.1037/0022-3514.63.4.596.

Bae, H. S. (2008). Entertainment-education and recruitment of cornea donors: The role of emotion and issue involvement. Journal of Health Communication, 13(1), 20-36. http://dx.doi.org/10.1080/10810730701806953.

Baumeister, R. F., \& Leary, M. R. (1995). The need to belong: Desire for interpersonal attachments as a fundamental human motivation. Psychological Bulletin, 117(3), 497-529. http://dx.doi.org/10.1037/0033-2909.117.3.497.

Baumeister, R. F., Vohs, K. D., \& Funder, D. C. (2007). Psychology as the science of self-reports and finger movements: Whatever happened to actual behavior. Perspectives on Psychological Science, 2(4), 396-403. http://dx.doi.org/10.1111/j.1745-6916.2007.00051.x.

Becker, J., Johnston, D., Daly, M., Paton, D., Mamula-Seadon, L., Petersen, J., ... Williams, S. (2011). Building community resilience to disasters: A practical guide for the emergency management sector. GNS Science Report, 9.

Becker, J., Paton, D., \& Johnston, D. (2015). Communication of Risk: A communicaty resilience perspective. GNS Science Report, $2015,66$.

Benight, C. C. (2004). Collective efficacy following a series of natural disasters. Anxiety Stress \& Coping, 17(4), 401-420. http://dx.doi.org/10.1080/ 10615800512331328768.

Broom, G. M., Casey, S., \& Ritchey, J. (1997). Toward a concept and theory of organization-public relationships. Journal of Public Relations Research, 9(2), 83-98.

Broom, G. M., Casey, S., \& Ritchey, J. (2000). Concept and theory of organization-public relationships. Public relations as relationship management: A relational approach to the study and practice of public relations $3-22$.

Claeys, A.-S., Cauberghe, V., \& Leysen, J. (2013). Implications of stealing thunder for the impact of expressing emotions in organizational crisis communication. Journal of Applied Communication Research, 41(3), 293-308. http://dx.doi.org/10.1080/00909882.2013.806991.

Coombs, W. T. (2004). Impact of past crises on current crisis communication: Insights from situational crisis communication theory. The Journal of Business Communication, 41(3), 265-289. http://dx.doi.org/10.1177/0021943604265607 1973.

Coombs, W. T. (2007). Protecting organization reputations during a crisis: The development and application of situational crisis communication theory. Corporate Reputation Review, 10(3), 163-176. http://dx.doi.org/10.1057/palgrave.crr.1550049.

Coombs, W. T. (2014). Ongoing crisis communication: Planning, managing, and responding. Sage Publications.

Cuddy, A. J., Fiske, S. T., \& Glick, P. (2008). Warmth and competence as universal dimensions of social perception: The stereotype content model and the BIAS map. Advances in Experimental Social Psychology, 40, 61-149. http://dx.doi.org/10.1016/S0065-2601(07)00002-0.

Cuddy, A. J., Glick, P., \& Beninger, A. (2011). The dynamics of warmth and competence judgments, and their outcomes in organizations. Research in Organizational Behavior, 31, 73-98. http://dx.doi.org/10.1016/j.riob.2011.10.004.

Davis, M. H., Soderlund, T., Cole, J., Gadol, E., Kute, M., Myers, M., \& Weihing, J. (2004). Cognitions associated with attempts to empathize: How do we imagine the perspective of another. Personality and Social Psychology Bulletin, 30(12), 1625-1635. http://dx.doi.org/10.1177/0146167204271183.

De Waal, F. B. (2008). Putting the altruism back into altruism: The evolution of empathy. Annual Review of Psychology, 59, 279-300. http://dx.doi.org/10.1146/ annurev.psych.59.103006.093625.

Decety, J., \& Jackson, P. L. (2004). The functional architecture of human empathy. Behavioral and Cognitive Neuroscience Reviews, 3(2), 71-100. http://dx.doi.org/10. $1177 / 1534582304267187$.

Duijnhoven, H., Neef, M., Davis, S., Dinesen, C., \& Kerstholt, J. H. (2016). Resilient communities: Implications for professionals. Paper presented at the 6th international conference on building resilience.

Eisenberg, N., \& Miller, P. A. (1987). The relation of empathy to prosocial and related behaviors. Psychological Bulletin, 101(1), 91-119. http://dx.doi.org/10.1037/ 0033-2909.101.1.91.

Fanelli, D. (2010). Do pressures to publish increase scientists' bias? An empirical support from US States Data. PloS One, 5(4), e10271.

Faraji-Rad, A., Samuelsen, B. M., \& Warlop, L. (2015). On the persuasiveness of similar others: The role of mentalizing and the feeling of certainty. Journal of Consumer Research, 42(3), 458-471. http://dx.doi.org/10.1093/jcr/ucv032.

Fehr, R., \& Gelfand, M. J. (2010). When apologies work: How matching apology components to victims' self-construals facilitates forgiveness. Organizational Behavior and Human Decision Processes, 113(1), 37-50. http://dx.doi.org/10.1016/j.obhdp.2010.04.002.

Fiske, S. T., Cuddy, A. J., \& Glick, P. (2007). Universal dimensions of social cognition: Warmth and competence. Trends in Cognitive Sciences, 11(2), 77-83. http://dx. doi.org/10.1016/j.tics.2006.11.005.

Frewer, L. J., Howard, C., Hedderley, D., \& Shepherd, R. (1996). What determines trust in information about food-related risks? Underlying psychological constructs. Risk Analysis, 16(4), 473-486. http://dx.doi.org/10.1111/j.1539-6924.1996.tb01094.x.

Griffin, M., Babin, B. J., \& Darden, W. R. (1992). Consumer assessments of responsibility for product-related injuries: The impact of regulations, warnings, and promotional policies. In J. F. Sherry, \& B. Sternthal (Vol. Eds.), NA-advances in consumer research: Vol. 19, (pp. 870-878). Provo. UT: Association for Consumer Research.

Gutteling, J. M., \& De Vries, P. W. (2016). Determinants of seeking and avoiding risk-related information in times of crisis. Risk Analysis, 37(1), 27-39. http://dx.doi. 
$\operatorname{org} / 10.1111 /$ risa.12632.

Jin, Y., Liu, B. F., \& Austin, L. L. (2014). Examining the role of social media in effective crisis management: The effects of crisis origin, information form, and source on publics' crisis responses. Communication Research, 41(1), 74-94. http://dx.doi.org/10.1177/0093650211423918.

Joustra, T. H. J., Brouwer-Korf, A. H., Mertens, F. J. H., Muller, E. R., \& Visser, J. P. (2012). Fire at Chemie-pack Moerdijk. The Hague: Dutch Safety Board.

Ledingham, J. A., \& Bruning, S. D. (1998). Relationship management in public relations: Dimensions of an organization-public relationship. Public Relations Review, 24(1), 55-65.

Ledingham, J. A. (2001). Government-community relationships: Extending the relational theory of public relations. Public Relations Review, 27(3), 285-295.

Lee Jenni, G. D., Peterson, M. N., Katz Jameson, J., \& Cubbage, F. W. (2015). Military perspectives on public relations related to environmental issues. Journal of Public Relations Research, 27(4), 353-369.

Lee, B. K. (2004). Audience-oriented approach to crisis communication: A study of Hong Kong consumers' evaluation of an organizational crisis. Communication Research, 31(5), 600-618. http://dx.doi.org/10.1177/0093650204267936.

Li, H. Z., Zhang, Z., Bhatt, G., \& Yum, Y.-O. (2006). Rethinking culture and self-construal: China as a middle land. The Journal of Social Psychology, 146(5), 591-610. http://dx.doi.org/10.3200/SOCP.146.5.591-610.

Lindell, M. K., \& Perry, R. W. (2012). The protective action decision model: Theoretical modifications and additional evidence. Risk Analysis, 32(4), 616-632. http:// dx.doi.org/10.1111/j.1539-6924.2011.01647.x.

Lindell, M. K., \& Whitney, D. J. (2000). Correlates of household seismic hazard adjustment adoption. Risk Analysis, 20(1), 13-26. http://dx.doi.org/10.1111/02724332.00002.

McDonald, L. M., Sparks, B., \& Glendon, A. I. (2010). Stakeholder reactions to company crisis communication and causes. Public Relations Review, 36(3), 263-271. http://dx.doi.org/10.1016/j.pubrev.2010.04.004.

Norris, F. H., Stevens, S. P., Pfefferbaum, B., Wyche, K. F., \& Pfefferbaum, R. L. (2008). Community resilience as a metaphor, theory, set of capacities, and strategy for disaster readiness. American Journal of Community Psychology, 41(1-2), 127-150.

Parks, M. R., \& Floyd, K. (1996). Meanings for closeness and intimacy in friendship. Journal of Social and Personal Relationships, 13(1), 85-107. http://dx.doi.org/10. $1177 / 0265407596131005$.

Paton, D., Smith, L., Daly, M., \& Johnston, D. (2008). Risk perception and volcanic hazard mitigation: Individual and social perspectives. Journal of Volcanology and Geothermal Research, 172(3), 179-188. http://dx.doi.org/10.1016/j.jvolgeores.2007.12.026.

Paton, D., Sagala, S., Okada, N., Jang, L.-J., Bürgelt, P. T., \& Gregg, C. E. (2010). Making sense of natural hazard mitigation: Personal, social and cultural influences. Environmental Hazards, 9(2), 183-196. http://dx.doi.org/10.3763/ehaz.2010.0039.

Paton, D. (2013). Disaster Resilient Communities: Developing and testing an all-hazards theory. IDRiM Journal, 3(1), 1-17.

Perkins, D. D., Hughey, J., \& Speer, P. W. (2002). Community psychology perspectives on social capital theory and community development practice. Community Development, 33(1), 33-52. http://dx.doi.org/10.1080/15575330209490141.

Peters, R. G., Covello, V. T., \& McCallum, D. B. (1997). The determinants of trust and credibility in environmental risk communication: An empirical study. Risk Analysis, 17(1), 43-54. http://dx.doi.org/10.1111/j.1539-6924.1997.tb00842.x.

Petty, R. E., \& Cacioppo, J. T. (1996). Addressing disturbing and disturbed consumer behavior: Is it necessary to change the way we conduct behavioral science. Journal of Marketing Research, 33(1), 1-8. http://dx.doi.org/10.2307/3152008.

Pieniak, Z., Verbeke, W., Scholderer, J., Brunsø, K., \& Olsen, S. O. (2007). European consumers' use of and trust in information sources about fish. Food Quality and Preference, 18(8), 1050-1063. http://dx.doi.org/10.1016/j.foodqual.2007.05.001.

Regan, Á., McConnon, Á., Kuttschreuter, M., Rutsaert, P., Shan, L., Pieniak, Z., ... Wall, P. (2014). The impact of communicating conflicting risk and benefit messages: An experimental study on red meat information. Food Quality and Preference, 38, 107-114. http://dx.doi.org/10.1016/j.foodqual.2014.05.019.

Renn, O., \& Levine, D. (1991). Credibility and trust in risk communication. Communicating risks to the public: International perspectives. Dordrecht, The Netherlands: Kluwer Academic Publishers175-218.

Reynolds, B., \& Seeger, M. W. (2005). Crisis and emergency risk communication as an integrative model. Journal of Health Communication, 10(1), 43-55. http://dx.doi. org/10.1080/10810730590904571.

Rosenberg, S., Nelson, C., \& Vivekananthan, P. (1968). A multidimensional approach to the structure of personality impressions. Journal of Personality and Social Psychology, 9(4), 283. http://dx.doi.org/10.1037/h0026086.

Seeger, M. W. (2006). Best practices in crisis communication: An expert panel process. Journal of Applied Communication Research, 34(3), 232-244. http://dx.doi.org/ 10.1080/00909880600769944.

Shen, L. (2010). Mitigating psychological reactance: The role of message-induced empathy in persuasion. Human Communication Research, 36(3), 397-422. http://dx. doi.org/10.1111/j.1468-2958.2010.01381.x.

Siegrist, M. (2000). The influence of trust and perceptions of risks and benefits on the acceptance of gene technology. Risk Analysis, 20(2), 195-204. http://dx.doi.org/ $10.1111 / 0272-4332.202020$.

Silvia, P. J. (2005). Deflecting reactance: The role of similarity in increasing compliance and reducing resistance. Basic and Applied Social Psychology, 27(3), 277-284. http://dx.doi.org/10.1207/s15324834basp2703_9.

Steelman, T. A., \& McCaffrey, S. (2013). Best practices in risk and crisis communication: Implications for natural hazards management. Natural Hazards, 65(1), 683-705. http://dx.doi.org/10.1007/s11069-012-0386-z.

Steelman, T. A., McCaffrey, S. M., Velez, A.-L. K., \& Briefel, J. A. (2015). What information do people use, trust, and find useful during a disaster? Evidence from five large wildfires. Natural Hazards, 76(1), 615-634. http://dx.doi.org/10.1007/s11069-014-1512-x.

Stubbé, H. E., Emmerik, M. L., \& Kerstholt, J. H. (2017). Helping behavior in a virtual crisis situation: Effects of safety awareness and crisis communication. Journal of Risk Research, 20(4), 433-444. http://dx.doi.org/10.1080/13669877.2015.1071865.

Sutton, J. N., Palen, L., \& Shklovski, I. (2008). Backchannels on the front lines: Emergency uses of social media in the 2007 Southern California Wildfires. University of Colorado.

Sweetser, K. D., \& Metzgar, E. (2007). Communicating during crisis: Use of blogs as a relationship management tool. Public Relations Review, 33(3), 340-342. http://dx. doi.org/10.1016/j.pubrev.2007.05.016.

Ulmer, R. R., Sellnow, T. L., \& Seeger, M. W. (2013). Effective crisis communication: Moving from crisis to opportunity. Sage Publications.

VanVoorhis, C. W., \& Morgan, B. L. (2007). Understanding power and rules of thumb for determining sample sizes. Tutorials in Quantitative Methods for Psychology, 3(2), 43-50.

Warshaw, P. R., \& Davis, F. D. (1985). Disentangling behavioral intention and behavioral expectation. Journal of Experimental Social Psychology, 21(3), 213-228. http://dx.doi.org/10.1016/0022-1031(85)90017-4.

Wiegman, O., \& Gutteling, J. M. (1995). Risk appraisal and risk communication: Some empirical data from the Netherlands reviewed. Basic and Applied Social Psychology, 16(1-2), 227-249.

Woosnam, K. M. (2010). The inclusion of other in the self (IOS) scale. Annals of Tourism Research, 37(3), 857-860. http://dx.doi.org/10.1016/j.annals.2010.03.003. 